\title{
Desain Gedung Tinggi Beton Bertulang Tahan Gempa
}

\author{
Oleh : Dradjat Hoedajanto
}

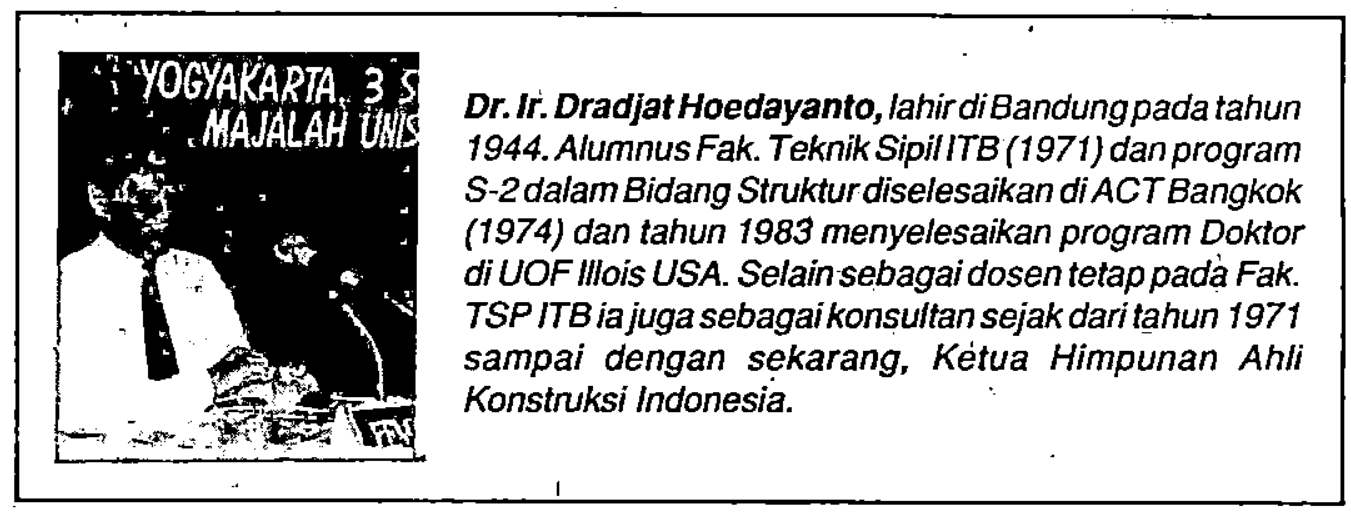

Pendahuluan

Desain dari Gedung Tinggi Beton Bertulang Tahan Gempa di Indonesia " diatru" oleh dua standar yaitu SNI Gempa - 1989 [1] dan SNI Beton - 1991 [2]. Keduanya, 'secara gabungan, memberikan tuntunan dasar mengenai (a) Konsep dan Kriteria Desain, dan(b) Beban Desain yang telah cukup dikenal dan dibicarakan secara terbuka. Hal yang diangkat pada kesempatan ini adalah hal yang berkaitan dengan Desain Gedung Beton Bertulang Tahan Gempa dengan kriteria tambahan khusus, TINGGI. Kriteria tambahan ini secara tidak langsung memberikan masalah khusus bagi perencanaan Indonesia, karena 'dalam khasanah istilah teknik konstruksi yang ada di Jakarta, kata Gedung 'Tinggi pada saat ini umumnya dikaitkan dengan. gedung yang mempunyai lapis di atas $\mathbf{5 0}$ lantai. Dalam hal ini pengalaman yang ada di Indonesia saat ini dapat dikatakan masih sangat terbatas dan belum dicakup dengan baikdalam rekomendasi pada Standar yang berlaku, termasuk belum jelasnya ketentuan mengenai beban gempa desain yang harus digunakan. Dalam SNLGempa - 89 respon spektra desain yang ada hanya mencakup ketentuan mengènai beban desain untuk gedung dengan periode dasarhingga 3 detik. Padahal gedung di atas 50 lantai kemungkinan besár akan mempunyai perioda dasar di atas 3 detik, dan bahkan untuk sistem struktur yang "normal"umumnya perioda dasamya akan mendekati 5 detik ke atas. Juga aspek 3 Dimensi dari masalah desain kurang dibahas secara mendetail karena ketentuan yang ada masih banyak "diarahkan" pada upaya untuk mengakomodasikan metoda analisis 2 Dimerisi.

Hal penting yang perlu dipegang agar langkah desain Gedung Tinggi Beton Bertulang Tahan Gempa dapat berjalan ke 
arah yang benar antara lain adanya pengertian yang baik mengenai :

1. Gempa dan gerakan tanah akibat gempa.

2. Konsep dasar respon struktur terhadap beban gempa.

3. Konsep dasar dari perílaku komponen struktur beton' akibat gempa.

4. Philosophi dasar dari standar yang diipakai

5. Pengaruh dari ketinggian terhadap gedung dan masyarakat secara keseluruhan.

Karena keterbatasan waktu yang ada dạn telah banyaknya bahasan yang berkaitan dengan gempa dan perilaku dasar dari komponen beton bertulang terhadap beban gempa, maka pada kesempatan ini perhatian utama dari bahasan ditujukan pada masalah yang berkaitan dengan karakter khusu yang mewarnai pengarüh dari ketinggian gedung yang didesain.

\section{Konsep Desain}

Masalah utama yang dihadapi dalam mendesain Gedung sangat tinggi adalah mengupayakan agar gedung tersebut mempunyai Kekuatan, Kekakuan, dan Stabilitas yang cukup terhadap segala kemungkinan kombinasi beban yang bekerja. Khusus untuk gedung tahan gempa, persyaratan lain yang umumnya dijadikan pegangan adalah mengupayakan agar komponen struktural gedung mempunyai daktilitas yang cukup agarmampu menahan gempa maksimum tanpa runtuh. Struktur gedung dalam hal ini dinamakan didesain dengan berdasarkan Life safety concept dan memberikan respon secara datail penuh. Perencanaan detail dari komponen struktur kemudian dilaksanakaan berdasarkan konsep Desain Kapasitas.

\section{Struktur tahan gempa}

Walaupun konsep Desain Kapasitas dapat dikatakan suatu konsepdesainstruktur tahan gempa yang diterima oleh hampir semua pihak, terdapat perbedaan yang cukup berarti antara konsep yang dianut oleh New Zealand, dan Amerika, terutama yang berkait dengan masalah "tingkat keamanan" Umum dikenal bahwa konsep desain struktur tahan gempa yang diangkat oleh NewZealand lebih rasional dan konsep yang dipakai oleh Amerika (termasuk Jepang) banyak didasarkan pada hasil studi empirik New Zealand menyampaikan pandangannya bahwa konsep desain yang dianut oleh Amerika tingkat keamanannya masih rendah dan perlu ditingkatkan agar tidak terjadi keruntuhan yang membahayakan.

Adanya perbedaan yang serius seperti tersebut di atas mendorong adanya stusi bersama yang secara tuntas berupaya untuk mempelajari kekurangan dan kelebihan masing-masing konsep desain. Studi perbandingan tadi dilaksanakan dengan melakukan test terhadap specimenspecimen yang sengaja dibuat sama dimensinya, tetapi berbeda. detail penulangan. Aoyama [3] melaporkan bahwa :

1. Semua specimen yang dibuat (detail dilaksanakan berdasarkan Codemasingmasing) dibebani berdasarkan kriteria beban yang sama.

2. Walaupun specimen New Zealand menunjukkan hasil yang memuaskan terhdap beban maksimum yang diberikan, mereka juga harus mengaku bahwa specimen Amerika dan Jepang yang detailnya tidak memenuhi kriteria desainmereka dan juga dibebani dengan 
beban yang sama mampu menunjukkan perilaku yang memuaskan.

Hasil ini menyukarkan New Zealand yang sebelumnya secara aktif mempromosikan konsep desain yang dianutnya. Perbedaan utama antra konsep New Zealand dan Amerika terletak pada metoda penghitungan tulangan baja yang diperiukan untukmenjamin terciptanya konsepKolomKuat-Balok-Lemah. Konsep New Zealand menghasilkan tulangan yang lebih banyak, yang secara langsung berarti lebih mahal. Mengingat Indonesia pada dasarnya mengikuti secaraterbatas rekomendasi New Zealand, hasil studi di atas perlu dikaji dengan teliti, apalagi dalam penggunaannya untuk mendesain gedung yangsangat tinggi.

\section{Gedung tinggi tahan gempa}

Untuk mendapatkan respon yang baik, syarat utama yang harus dipenuhi adalah agar struktur gedung tadi sejak awal sudahdirancang sedemikian hingga mampu mengantisipasi beban yang ada, terutama pengaruhbebanlateral, danberfungsi sesuai yang diharapkan '. Beberapa kunci utama yang perlu diperhatikan dalam mencari konsep struktur yang baik adalah :

1. Mengupayakan agarfundamental modes yang ada tidak berdekatan (tidák terjadi " coupling" dari "response"). Hal ini dicapai antara lain dengan mengambil langkah agar pada tiap lantai didapat suatu kontinuitas vertikal yang teratur. Bila pada bagian tertentu ada komponen vertikal yang harus dihilangkan karena kebutuhan non struktural, fungsi dari komponen tadi harus digantikan dengan komponen lain (ditambhakan) sehingga didapat hasil akhir yang baik.

2. Mengupayakan konsep struktur yang "sederhana",flow of forcesnya Misalnya konsep "tubes", outrigger frames", "perimeterbracings", "kombinasi "core" dan "frame", dan sebagainya.

3. Memikirkan kemudahan pelak-sanaan, termasuk pemilihan material struktur. Untuk gedung sangat tinggi data yang didapat dari beberap proyek menunjukkan bahwa sistem kolom kompositmerupakan solusi yang terbaik dan termurah untuk mengatasi keterbatasan kekuatan beton yang langsung dibebani oleh ketinggian gedung tersebut. "Very high strength concrete", walaupun sudah mungkin (di laboratorium) dan sudah di laksanakan (di luar negeri, misalnya USA), masih belum praktis untuk diadopsi di Indonesiaterutamakarenaketerbatasankualitas bahan yang ada.

4. Analisis struktur dengan sofware komersiil yang ada perlu dilaksanakan dengan sangat hati-hati. Bagaimanapun pameo GIGO - " Garbage In Garbage Out" masih berlaku.Perencana strutur perlu mengetahui keterbatasan dari software yang digunakan, terutama bila menggunakan metoda Elemen Hingga, dan juga analisis non-linear. Output yang dihasilkan perlu "diperiksa" dengan seksama, baik terhadap kemungkinan kesalahan input maupun kemungkinan kesalahan yang diakibatkan oleh asumsi yang diambil oleh software yang dipakai.

5. Khusus untuk analisis terhadap beban gempa, perlu dipahami konsep dasar

1. Sesuai konsepdesainyang diambil, apakah didesain dengan konsep "damage controlled design concept" atau "life safety design concept". 
dari pengambilan beban dan ketentuan ketentuan lain yang dipakai. Misalnya keterbatasan mengenai pemakaian analisis 2-D untuk bangunan di atas 40 $m$ dan lain lainya. Tanpa pengertian yang baik dari ketentuan dan rekomendasi Standar yang ada bisa menghasilkan struktur yang tidak jelas posisinya terhadap keamanan yang kita inginkan.

\section{Studi Kasus}

Untuk mendapatkan gambaran yang lebih baik mengenai desain dari Gedung Tinggi Beton Bertulang tahan Gèmpa, dilakukan bahasan mengenai gedung Zhimizu Super High-Rise setinggi $550 \mathrm{~m}$ yang telah didesain oleh Zhimizu Corporation di Tokyo. Langkah ini diambil karena terbatasnya informasi dan data aktual yang ada.Juga sekaligus langkah ini memberikan kesempatan kepada kita untuk mempelajari konsep-konsep dasar yang diterapkan oleh team ahli (350 orang engineers full time yang dikepalai oleh Prof. $M$. Watabe, bekerja selama 2 tahun) yang bukan hanya mendasarkan pilihan desainnya pada Code yang ada (karena belum ada Code yang mengatur gedung super tinggi) tetapi juga didasarkan pada penelitian dan diskusi dengan masyarakat dan pimpinan pemerintah setempat.

\section{Shimizu super high-rise building}

Shimizu Super High-Rise adalah gedung yang akan dibangun oleh Zhimizu di pinggiran kota Tokyo. Gedung ini direncanakan meimpunyai ketinggian akhir $550 \mathrm{~m}$ dan direncanakan selesai dibangun pada tahun 2005. Saat ini yang telah selesai dilaksanakan adalah Pekerjaan Desain dan studi prototype pelaksanaan yang direncanakan meng-gunakan teknik "robotic" penuh. Deskripsi dari proyek secara detail dapat dilihat pada Appendix A. Bahasan berikut merupakan evaluasi konseptual berkaitan dengan pola desain yang diambil.

\section{Sistem struktur}

Desain dan analisis dilakukan secara full time oleh team engineers selama dua tahun, dengan biaya total lk. US $\$$ $50,000,000.00$. Analisis dinamik dilakukan baik secara elastik maupun secara inelastik dengan menggunakan super computer. "Run time" dari satu kali analisis dinamik inelastik dengan super komputer setingkat Cray tersebut mencapai dua hari. Desain akhirnya scpenuhnya menggunakan analisis elastik.

Komponen vertikal secara konsep dibagi dalam tiga zona. Makin ke atas makin kecil. Konsep ini sesuai dengan hasil. studi yang menunjukkan bahwa konsep bangunan sangat tinggi yang paling efisien didapat pada sistim struktur yang mengecil keatas (terhadap beban lateral).

Pengaturan ruangan dibuat simetris, dengan tujuan utama menghindarkan terjadinya coupling antar mode responses yang berdekatan. Konsep struktur yang didesain sekaligus terhadap beban angin (angin topan) dan beban gempa artificial maksimum ( $8 M$ dengan jarak $200 \mathrm{~km}$ ). Terlihat konsep respon bangunan terhadap beban lateral sangat diperhatikan, dan bahkanmerupakan kunci utamadari konsep struktur yang ada. Konsep perlawanan terhadap beban lateral dinamik ditumpukan pada sistem kombinasi antara "tube action" dengan "perimeter truss bracing system" 
("Trussed Tube system"). Kolom menggunakan penampang komposit, antara beton dengan kekuatan $60 \mathrm{Mpa}$ dengan Baja profil mutu tinggi. Sistem komol komposit ini (SRC Columns) merupakan sistem yang paling efisien. Penggunaan beton komposit ini digabungkan dengan penggunaan "super-lightweight concrete" untuk "extra light floor system".

Beban gempa artificial yang dipakai diturunkan untuk kondisi 8M dan jarak 200 $\mathrm{km}$. Struktur sepenuhnya memberikan responsecara elastik. Analisis yang dipakai menggunakan "analisis time-history", dengan beban selama 500 detik. Fundamental period dari bangunan $1 \mathrm{k}$. 6 detik, dan perilaku dinamik dari struktur dibantu oleh sistem active damper ("Hybrid Mass Damper") yang dipasang nantinya pada puncak bangunan. Kebijakan untuk mengadopsi respon elastik penuh didapat dari hasil diskusi dengan pejabat setempat, yang "mengkhawatirkan" konsep awal yang diajukan Zhimizu yang mendasarkan analisis gempanya pada respon in-elastik. Kelihatannya kekhawatiran akan kemungkinan keruntuhan dari bangunan super tinggi ini sangat besar hingga konsep "ductile struktural response" tidak diterima. Analisis terhadap beban gempa dilakukan dengan memperhitungkan kontribusi dari respon pondasi ("soil structure interaction").

Sistem pondasi terlihat sangat kokoh. Hal ini diambil terutamauntukmemberikan "pegangan" yang baik terhadap gedung agar mempunyai kestabilan cukup akibat beban lateral dinamik (baik oleh angin maupun gempa). Teknologi diaphragm wall yang dipakai, tebal $4 \mathrm{~m}$, merupakan aplikasi dari teknik pembuatan tanki bawah tanah yang banyak terdapat di Jepang.

\section{Kesimpulan}

Mendesain dan melaksanakan Gedung Tinggi Beton Bertulang Tahan Gempa memerlukan pemikiran, penguasaan teknologi, dan inofasi engineering yang berbobot, terutama bila gedungnyamakintinggi. Hal ini bisadicapai bila dapat dikombinasikanunsur-unsur teori yang ditunjang dengan penelitian yang mendalam, dengan unsur praktek yang menghasilkan pola konstruksi yang memanfaatkan teknologi yang ada secara optimum. Keseluruhannya bisaberhasilbila ditunjang oleh konsep strikturyang mapan.

\section{Daftar Referensi}

Standar, TataCaraPerencanaan Ketahanan Gempa untuk Rumah dan Gedung, SNI-176-1989-F, Departemen Pekerjaan Umum, LPMB, 1989.

Standar, Tata Cara Penghitungan Struktur Beton untuk Bangunan Gedung, SK SNI T-15-1991-03, Departemen Pekerjaan Umum, Yayasan LPMB, Bandung.

Aoyama, H., "Engineering vs. Rational Approach in Structural Engineering, What We Learned From New Zealand - In the Trilateral Cooperative Research on Beam-Column Joints., Proceedings of the Tom Paulay Simposium, "Recent Developments in Lateral Force Transfer in Buildings", September 2022, 1993. La Jolla, California.

Zhimizu Corporation, "Shimizu Super HighRise", technical leaflet, 1994. 


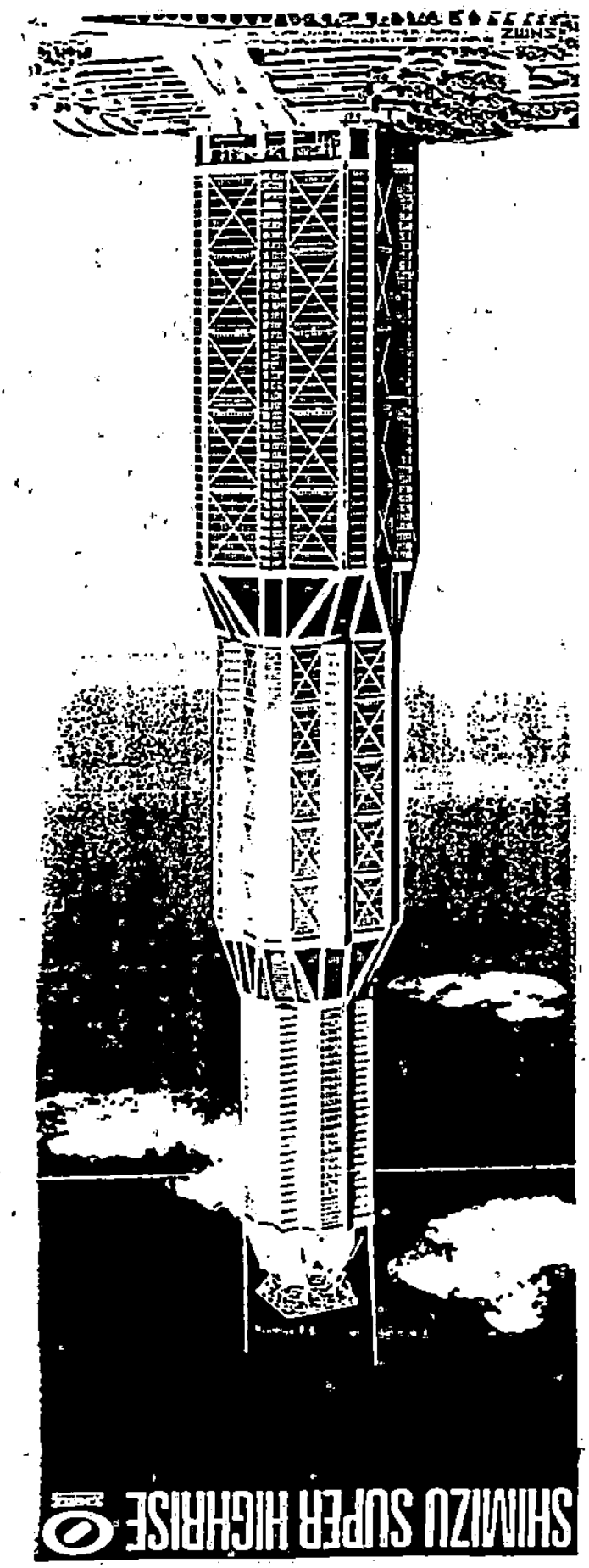




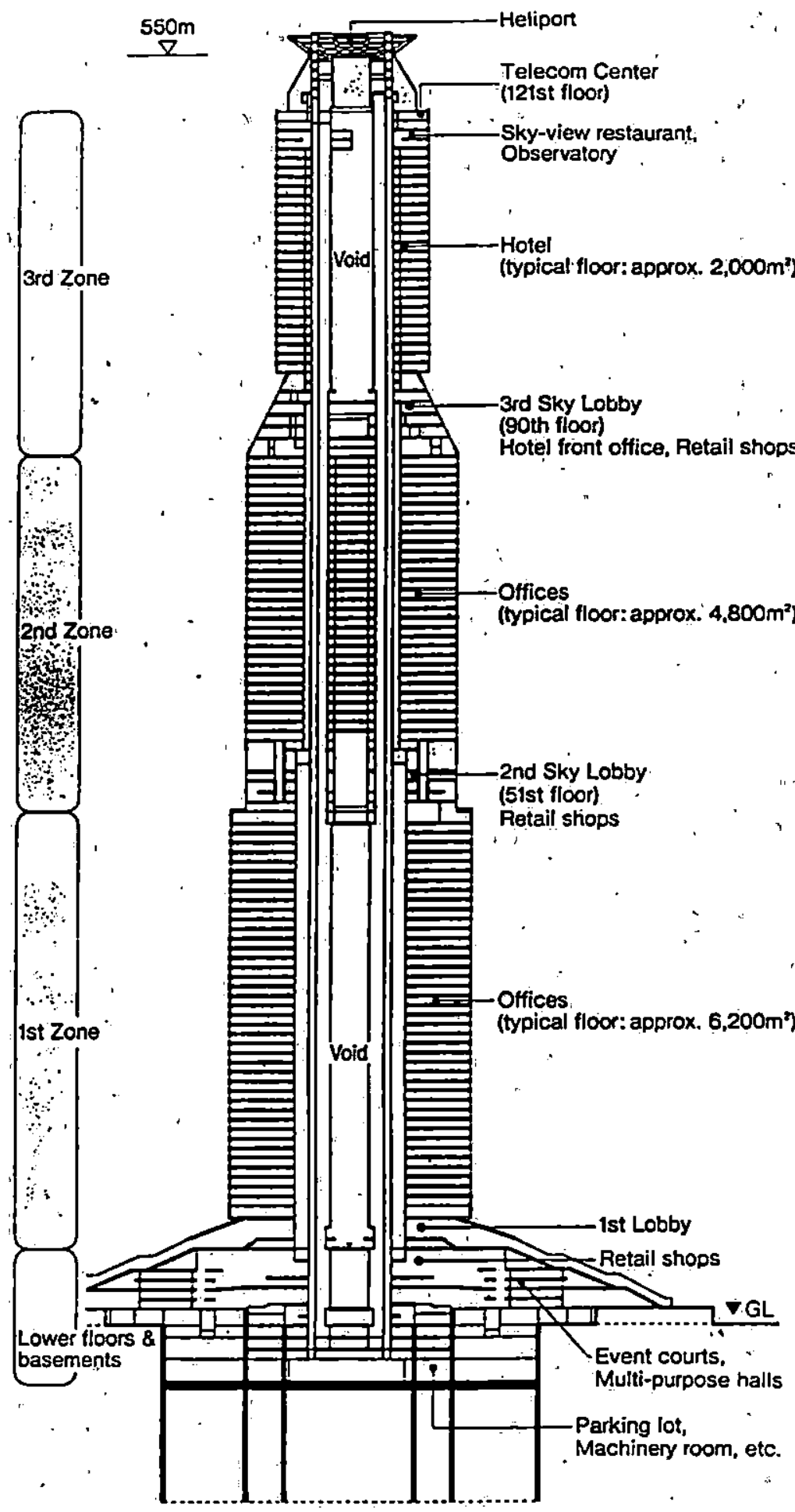

